\title{
VOLTAGE REGULATION AND DROOP CONTROL OF ELECTRIC SPRING USING SINGLE PHASE CASCADED H-BRIDGE INVERTER FOR STABILIZING SMART GRID
}

\author{
Chetna Jangade, Kalyani Gajbhiye, Pavan Fuke, Payal Dahiwale, \\ Samruddhi Bharati, Tina Patil, S.P.Gawande \\ Department of Electrical Engineering, \\ Yeshwantrao Chavan College of Engineering, Nagpur- 441110.
}

\begin{abstract}
This paper proposes "Electric Spring" (ES) based on Single Phase three-level Cascaded H-Bridge Inverter to achieve effective demand side management for stabilizing smart grid fed by substantial intermittent renewable energy sources (RES). Considering the most attractive features of multilevel inverter (MLI), an effective structure of Electric Spring is proposed for suppressing voltage fluctuation in power distribution network arising due to RES and maintaining the critical load voltage. Also, the operation of ES in capacitive as well as inductive mode is discussed. Further, the paper describes droop control method for parallel operation of distributed electric spring for stabilization the power grid. An exclusive dynamic performance of the system using electric spring has been tested and demonstrated through detailed MATLAB simulation.
\end{abstract}

Key Words : Critical load, Cascaded H-Bridge Inverter, Droop control, Electric Spring, MLI, RES, Smart load.

\section{Introduction}

Presently, the power is generated according to the load demand. But due to energy crises and the increase in consumer requirement, generated power by traditional method is not sufficient. So to satisfy the load demand, the penetration of intermittent renewable energy sources (RESs) into the power grid has been increased [1], [2]. The intermittent nature of RESs leads to major problems like the power imbalance, voltage instability, voltage fluctuation, etc. [3]. To overcome these power quality issues various types of FACTS devices like capacitor banks, capacitor reactor, Static Compensator (STATCOM), Dynamic Voltage Restorer (DVR) have been proposed [4]. Using their fast and dynamic controller's power quality issues can be effectively mitigated. However, these devices face the problem of cost, control complexity, etc. Therefore to overcome some of these limitations, a multilevel inverter based Single-phase Electric Spring (ES) is proposed in this paper.ES is basically power electronics based circuit and its concept is derived by implementing hook's law in electric realm. ES is different from traditional conventional custom power devices which improves the voltage profile of the power system. ES is applied to the Load Demand Side for stabilizing voltage fluctuation caused by renewable energy sources (RESs) [5], [6]. ES is low cost, autonomous device and although it is small power devices, multiple distributed electric springs can contribute to the robust stabilizing effect. The ES is connected in series with a non-critical load $(\mathrm{Znc})$ (i.e. The ES is connected in series with a non-critical load (Znc) (i.e.

This work is sponsored by Innovative Project Scheme \& In-house Project Proposal Grand 2016-17.

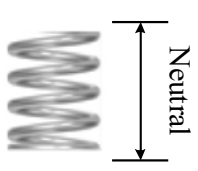

(a1)

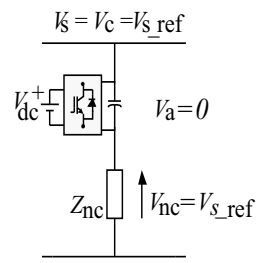

(a2)

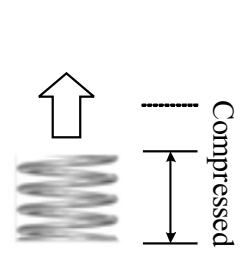

(b1)

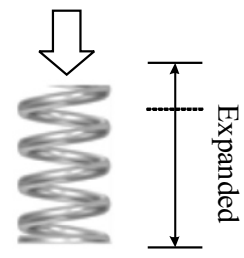

(c1)
Fig. 1 : Analogy between mechanical spring and an electrical spring where (a1) Neutral position, (a2) Neutral mode, (b1) Mechanical push (upward force), (b2) Voltage boosting function, (c1) Mechanical pull (downward force), (c2) Voltage reduction function.

less sensitive to voltage fluctuation) to form a smart load [7]. To obtain voltage regulation across the critical load (Zc) (i.e. voltage sensitive), the ES generates the compensation voltage or electric spring voltage (Va) which is perpendicular to the non-critical load current (Ia) [8].

Up till now electric spring using two-level inverter topology has been anatomized but this paper proposes ES using multilevel inverter (MLI). MLI topology has emerged recently as a most important alternative in stabi- 
lizing voltage fluctuation caused in power distribution network [9]. Some of the most attractive features of MLI are, it can generate output waveform which is more close to sinusoidal wave hence low distortion and lower dv/dt, they generate smaller common- mode (CM) voltage as compared to the conventional two-level inverter, operates with a lower switching frequency means lower switching loss and high efficiency Different type of MLI based topologies have been proposed with their several modulation and dynamic controls. One of such effective topology is Cascaded H-bridge inverter (CHMIL) [10]. CHMIL has advantages like it needs less number of components compared with diode clamped (DCI) and flying capacitor inverters (FCI) thus cost and weight of the inverter decreases. CHMLI are used to eliminate the bulky transformer required in case of conventional multiphase inverters, clamping diodes required in case of diode-clamped inverters and flying capacitors required in case of flying capacitor inverters but these require a large number of isolated voltages supply for each cell.

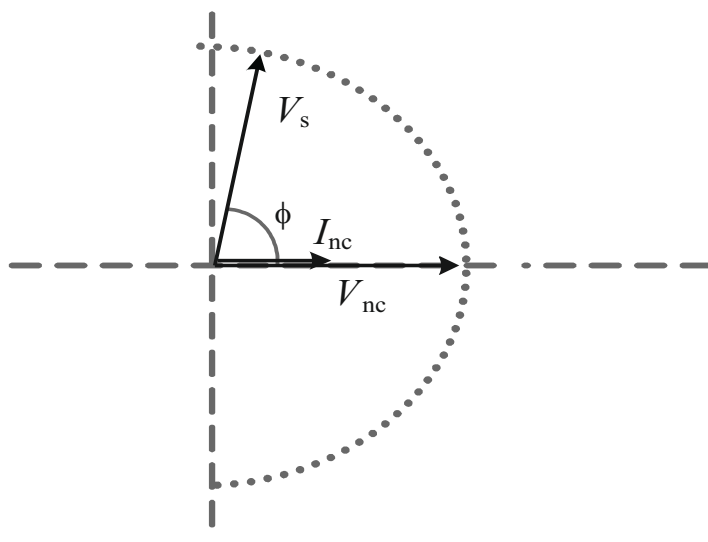

(a)

\section{Analogy Between Mechanical and Electric Spring}

\section{A. Hooks law in mechanical regime}

The mechanical spring has been a crucial component in mechanical engineering since Physicist Robert Hooke firstly smoked out its scientific principle in the 1660's [11]. The law gives the relationship between force and displacement. According to Hooke's law force $(F)$ is directly proportional to displacement $(\mathrm{x})$.i.e. when mechanical spring is stretched or compressed; the force it exerts is proportional to its change in displacement.

$$
\mathrm{F}=-k \mathrm{x}
$$

The potential energy (PE) store $d$ in a mechanical spring is :

$$
\mathrm{PE}=\frac{1}{2} k \mathrm{x}^{2}
$$

The mechanical spring is the elastic device which performs the function like: 1) It provides mechanical support; 2) It stores mechanical energy; 3) It damps the mechanical oscillations. Mechanical springs are widely used in many other applications such as toys, watches, vehicles, beds etc.

\section{A. Hooks law in electrical regime}

Similar to mechanical spring, ES in electric regime can perform various functions as follow: 1) It provides

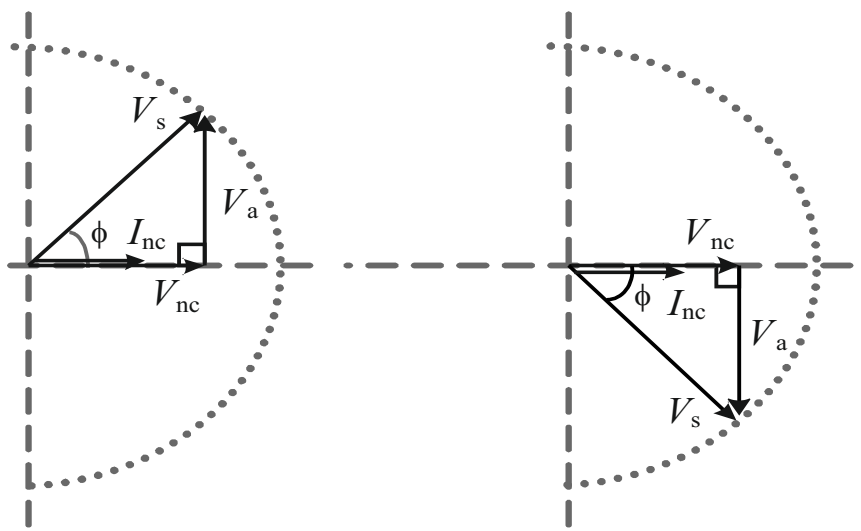

(b)

electric voltage support; 2) It stores electric energy; 3) It helps to damp the electric oscillation. Analogous to equation (1) the basic physical relationship of the ES is shown as follow:

$$
\begin{aligned}
& q= \pm \mathrm{C}_{f} V_{a} \\
& q=\int I_{a} d t
\end{aligned}
$$

Where $q$ is the electric charge stored in the capacitor of capacitance $\left(C_{f}\right)$ of the ES; Va is the electric potential difference across the capacitor. From equation (4) it can be concluded that by controlling the current $\left(I_{a}\right)$ flowing through the capacitor (i.e. indirectly by controlling the charging and discharging states of a capacitor) operating modes of electric spring can be determined as the neutral, the voltage boosting and the voltage suppression mode. Thus, the ES can be depicted as a controlled current source.

\section{Basic Principle and Operating Modes of Electric Spring}

Fig. 1 shows that the ES is connected in series with loss dissipative non-critical load $\left(Z_{n c}\right)$. This series combination of the ES and $Z_{n c}$ attached to PCC for stabilize the supply voltage $\left(V_{s}\right)$ to its nominal reference voltage $\left(\mathrm{V}_{\text {s_ref }}\right)$ which is originally $230 \mathrm{~V}$.

Electric spring is similar to mechanical spring under three operation modes. The neutral position case of mechanical 
spring entangles that force applied on mechanical spring is zero while for the ES, the neutral mode aids that the ES voltage $\left(V_{a}\right)$ is equal to zero shown in Fig. 1(a1)-(a2). Thus supply voltage $(V)$ and load voltage are equal to the nominal reference voltage $\left(V_{s \text { ref }}\right)$.The mechanical push (compression) case of mechanical spring is similar to voltage boosting mode of the ES. In this condition, when ES is bypassed the supply voltage $\left(V_{s}\right)$ and load voltage are less than the nominal reference voltage $\left(V_{s \text { ref }}\right)$. After ES is activated, the ES generates the voltage $V_{a}$ to boost $V_{s}$ up to $V_{s \text { ree }}$ shown in Fig. 1(b1)-(b2). In repugnance to mechanical push condition, the mechanical pull case of mechanical spring is similar to voltage suppression mode of ES. When ES is switched off, the supply voltage $\left(V_{s}\right)$ has higher magnitude than nominal refere-

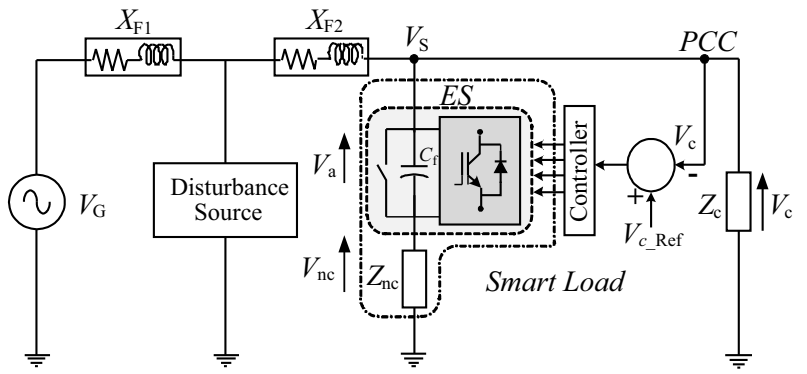

Fig. 3 : Schematic of power system with embedded Electric Spring

nce voltage $\left(V_{s_{\text {ref }}}\right)$. After ES is switched voltage $V_{s}$ to $V_{\text {s ref }}$ depicted in Fig. 1(c1)-(c2).

The vector sum of the compensation voltage or electric spring voltage $\left(V_{a}\right)$ and the noncritical load voltage $\left(V_{n c}\right)$ is equal to the supply voltage $\left(V_{s}\right)$ mathematically given by:

$$
V_{\mathrm{a}}+V_{\mathrm{nc}}=V_{\mathrm{s}}
$$

Fig. 2 shows the corresponding phasor diagram for the operating modes of ES. In neutral position the voltage of electric $\left(V_{a}\right)$ is zero and the supply voltage $V_{s}$ is equal to reference voltage $V_{s \text { ref }}$. When the mains voltage is less than its nominal reference voltage and the amount of the generated power is not enough to satisfy the load demand, then the electric spring works in capacitive mode (voltage boosting) to boost the mains voltage to its nominal reference voltage by producing Va at 90 lagging to the current $\left(I_{n c}\right)$ as shown in Fig. 2(b). In inductive mode, the mains voltage is greater than the nominal reference voltage then the electric spring operates to decreases the supply voltage to its nominal reference value, under this situation Va is 90 leading to the current $\left(I_{n c}\right)$ as outlined in Fig. 2(c). Thus inductive and capacitive modes of electric spring are two different modes similar to the mechanical spring that can change the displacement in either direction when mechanical force is applied. Consequently, the power consumption $\left(P_{l}\right)$ of the non-critical load can also be controlled, which is given by equation (6).

$$
\begin{gathered}
P_{\text {in }}=\frac{V_{\mathrm{s}}^{2}-V_{\mathrm{a}}^{2}}{R_{\mathrm{nc}}}+\frac{V_{\mathrm{s}}^{2}}{R_{\mathrm{c}}} \\
P_{\mathrm{in}}=P_{1}+P_{2}
\end{gathered}
$$

This indicates that, if supply voltage $\left(V_{s}\right)$ is kept constant by the MLI based electric spring then the only variable on the right-hand side of equation (6) is the compensation voltage $\left(V_{a}\right)$, where $R_{n c}$ and $R_{c}$ is a resistive non-critical load and resistive critical load respectively. The critical load power $\left(P_{2}\right)$ is a constant. The variation of the compensation voltage $\left(V_{a}\right)$ will adjust $P_{l}$ so that the sum of $P_{l}$ and $P_{2}$ will follow the profile of generated power $\left(P_{i n}\right)$. Thus electric spring is the special type of reactive power compensator (RPC) developed for decentralized installation and operation. It is different from a traditional series RPC which follows "an input feedback and input voltage control" [12]. This is done by regulating the input voltage $\left(V_{s}\right)$ and letting the output voltage to fluctuate dynamically (i.e. a new input voltage control) such type of RPC would provide: i) the line voltage support to nominal value, resulting in a stable voltage across a critical load $\left(Z_{c}\right)$ and ii) simultaneously allows the non-critical load $\left(Z_{c}\right)$ to consume the fluctuating power generated by the disturbance sources so that it automatically follow the power generation which is the new control paradigm.

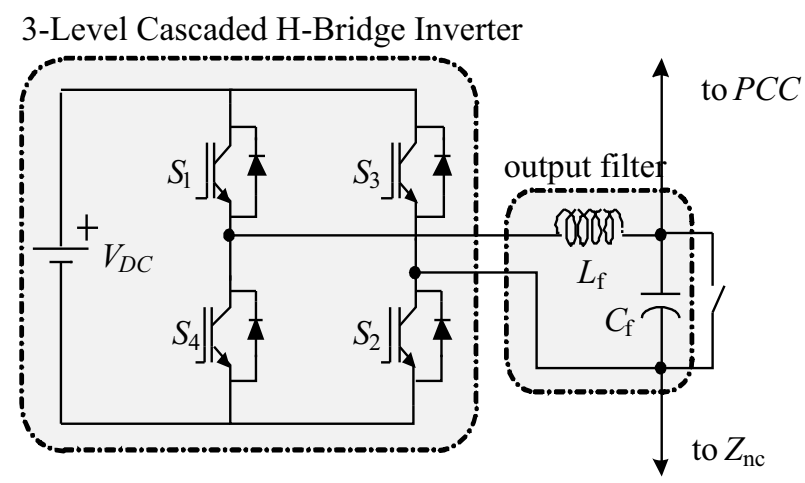

Fig. 4. Circuit diagram of Electric Spring

\section{Proposed Scheme and Control Strategy for Electric Spring}

\section{A. Proposed configuration of electric spring}

The proposed configuration of ES is shown in Fig. 3 consist of a power source to generate voltage $V_{g}$ feeding transmission impedances $X_{F 1}$ and $X_{F 2}$ respectively. In order to emulate a renewable energy source a disturbance source, capable of injecting variable active/reactive power is connected to power grid which is connected in parallel to non-critical load $\left(Z_{n c}\right)$ and critical load $\left(Z_{c}\right)$. In this analysis the performance of Electric Spring is evaluated by considering non-critical load $\left(Z_{n c}\right)$ and 
critical load $\left(Z_{c}\right)$ as the resistive load; however any type of load can be connected. To regulate the line voltage electric spring is integrated in series with a lossless dissipative non-critical load $\left(Z_{n c}\right)$ in the distribution system to form a new smart load through a capacitor $C_{f}$. The inverter forms the main component of ES which is connected to $C_{f}$ through filter inductor $L_{f}$. The inverter topology i.e. is single phase three-level Cascaded H-Bridge inverter is demonstrated in Fig. 4. It consists of four switches $S_{l}-S_{4}$ realized using IGBT/diodes and supported by a dc-link. In order to regulate the voltage at the point of common coupling (PCC) the electric spring voltage changes dynamically to regulate the mains voltage $\left(V_{s}\right)$ and also allow the load consumption to follow the power generation. This system is modeled using MATLAB and system parameters are demonstrated in Table 1.

\section{B. Control strategy for electric spring}

The operating principle of ES is different from traditional custom power devices. In the case of traditional custom power devices, output feedback control is used i.e., the output of the system is compared with the reference signal and then processed further; but for ES the input feedback control is used in which input signal is compared with its reference voltage. Fig. 5 shows a simple close loop control scheme derived reference $\left(V_{s \text { ref }}\right)$. Their difference is sent to Proportional-Integral $\left(P_{I}\right)$ controller whose output signal decides the magnitude of modulation index $\left(m_{a}\right)$. Based on this signal the mode specifier selects the mode of operation. In capacitive mode the mode specifier avows the current to lead the voltage by 90 whereas in inductive mode the mode specifier allows the current to lag behind the voltage by 90 . The other part of control scheme is Phase Locked Loop (PLL) controller which figures out the phase and frequency of electric spring voltage $\left(I_{a}\right)$. The reference signals for pulse generator are obtained by multiplying the product of modulation index $\left(m_{a}\right)$ and sinusoidal signal by half of DC link voltage $\left(V_{D C}\right)$. Various PWM schemes can be used to generate the pulse. In, this paper carrier based modulation scheme is employed where generated modulating signal $m(t)$ is compared with carrier wave by PWM generator to produce switching signals for the inverter (VSI)

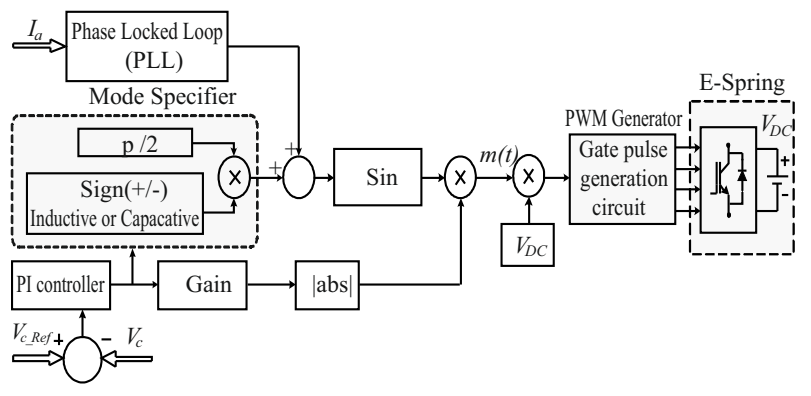

Fig. 5 : Simplified control block diagram

\section{Simulation Results}

\section{A. Inductive (voltage suppression) mode of operation of electric spring}

To test the voltage suppression capability of the ES a disturbance source is programmed at $t=0.2 \mathrm{sec}$ to generate a voltage of $245 \mathrm{~V}$ (i.e. $20 \mathrm{~V}$ higher than nominal value of $225 \mathrm{~V}$ ) shown in Fig. 6 (a). In order to suppress the increased line voltage back to its nominal reference value the ES is activated at $t=0.4 \mathrm{sec}$ and voltage of electric spring is changed to stabilize the line voltage as shown in Fig. 6 (b). As soon as ES is activated; it is observed that voltage across non-critical load increases as indicated in Fig. 6 (c). Finally it is seen from Fig. 6 (d) that the voltage is regulated back to its nominal reference value i.e. $225 \mathrm{~V}$. The corresponding instantaneous value of supply voltage, non-critical load voltage, electric spring voltage and critical load voltage are demonstrated in Fig. 7 (a) - (b) in which Fig. 7 (b) clearly indicates that current lags the voltage by $90^{\circ}$, representing efficacious working of the ES in inductive mode.

\section{B. Capacative (voltage boosting) mode of operation of electric spring}

To illustrate the voltage support capability of ES the disturbance source is programmed at $t=0.2 \mathrm{sec}$ to generate a voltage of $210 \mathrm{~V}$ (i.e. $15 \mathrm{~V}$ lower than nominal value of $225 \mathrm{~V}$ ) shown in Fig. 8(a). In order to restore the line voltage back to its nominal reference value the ES is activated at $t=0.4 \mathrm{sec}$ and voltage of the ES is increased from its near-zero value to about $160 \mathrm{~V}$. As soon as ES is activated, it is observed that voltage across non-critical load decreases to $157.7 \mathrm{~V}$ as indicated in Fig. 8(b)-(c). Finally it is seen from Fig. 8 (d) that the voltage is regulated back to its nominal reference value i.e. $225 \mathrm{~V}$. The corresponding instantaneous value of supply voltage, electric spring voltage and critical load voltage and current are demonstrated in Fig. 9 (a) - (b) in which Fig. 9 (b) clearly indicates that current leads the voltage by $90^{\circ}$. Thus successful implementation of ES in capacitive mode is conducted using MATLAB.

The simulation studies are also carried out using twolevel VSI based ES. Fig. 10 directly shows the comparative performance in terms of FFT analysis of compensated critical load voltage for two-level and three-level ES. It is seen that the three-level CHMLI based ES provides much reduced THD of $1.65 \%$ as compared two-level VSI based ES which is $2.19 \%$ meeting IEEE 519 harmonic standard. This proves the overall improved performance of ES using multilevel inverter as compared with two-level VSI based ES. 
TABLE I

System Parameter

\begin{tabular}{|c|c|c|}
\hline Description & Parameter & Value \\
\hline Supply voltage & $V_{\mathrm{s}}$ & 230 Volt \\
\hline Non-critical load & $Z_{\mathrm{nc}}$ & $19 \Omega$ \\
\hline Critical load & $Z_{\mathrm{c}}$ & $40 \Omega$ \\
\hline $\begin{array}{c}\text { Switching } \\
\text { frequency }\end{array}$ & $f_{\mathrm{sw}}$ & $1 \mathrm{KHz}$ \\
\hline Modulation index & $M$ & 0.98 \\
\hline DC voltage & $V_{\mathrm{dc}}$ & $250 \mathrm{Volt}$ \\
\hline Inductance & $L_{\mathrm{f}}$ & $500 \mathrm{mH}$ \\
\hline Capacitance & $C_{\mathrm{f}}$ & $200 \mu$ \\
\hline
\end{tabular}

\section{Role of Distributed Mli Based Electric Spring}

For parallel operation of distributed ES for stabilizing ac power grid, droop control methodology is employed. Fig. 12 shows four ES working as a group to support and stabilize the ac mains voltage levels at their respective location in distribution network. Since along the transmission line these ES's will be distributed and installed at divergent locations and the exact value of ac mains voltage which ES's are supposed to maintain at their respective nominal reference values are location specific. Therefore to generate respective nominal reference value, control used for ES is modified as shown in Fig. 11. This control scheme allows distributed ES's to have automatically adaptable references voltage according to the value of the main voltage level at their specific location.

The ES is assumed to be located at a distance $\mathrm{x}$ from the ac source which has a nominal reference value of $V_{s}^{*}$ and the ac main voltage at the location of ES is $V_{s x}$. The basic purpose of the proposed control scheme is to generate an adaptable reference voltage $V_{s x}{ }^{*}$, which is similar in characteristics to the actual mains voltage at $\mathrm{x}$ location. The measured value of voltage $V_{s x}$ is subtracted from the reference voltage $V_{s x}{ }^{*}$. The generated error signal is given to the PI controller whose output is given to the gain $(K)$ and this signal is subtracted from the $V^{*}$ to generate the adaptable voltage reference value.

The simulation results using droop control for inductive and capacitive mode of four ES working in distributed manner is illustrated in Fig. 13. At instant $t=0.2 \mathrm{sec}$ because of disturbance source, voltages at four different location increases above its nominal reference value $V_{s}$, $V_{s 2}, V_{s 3}, V_{s 4}$ and at $t=0.4 \mathrm{sec}$ it is observed that ES are activated and voltages are regulated back to their respective reference values; therefore ES operates effectively in capacitive mode of operation. During inductive mode of operation it is observed that at $t=0.6$ $\mathrm{sec}$ voltage drops from its nominal reference values and at $t=0.8 \mathrm{sec}$ ES activates to regulate respective voltages back to original value.
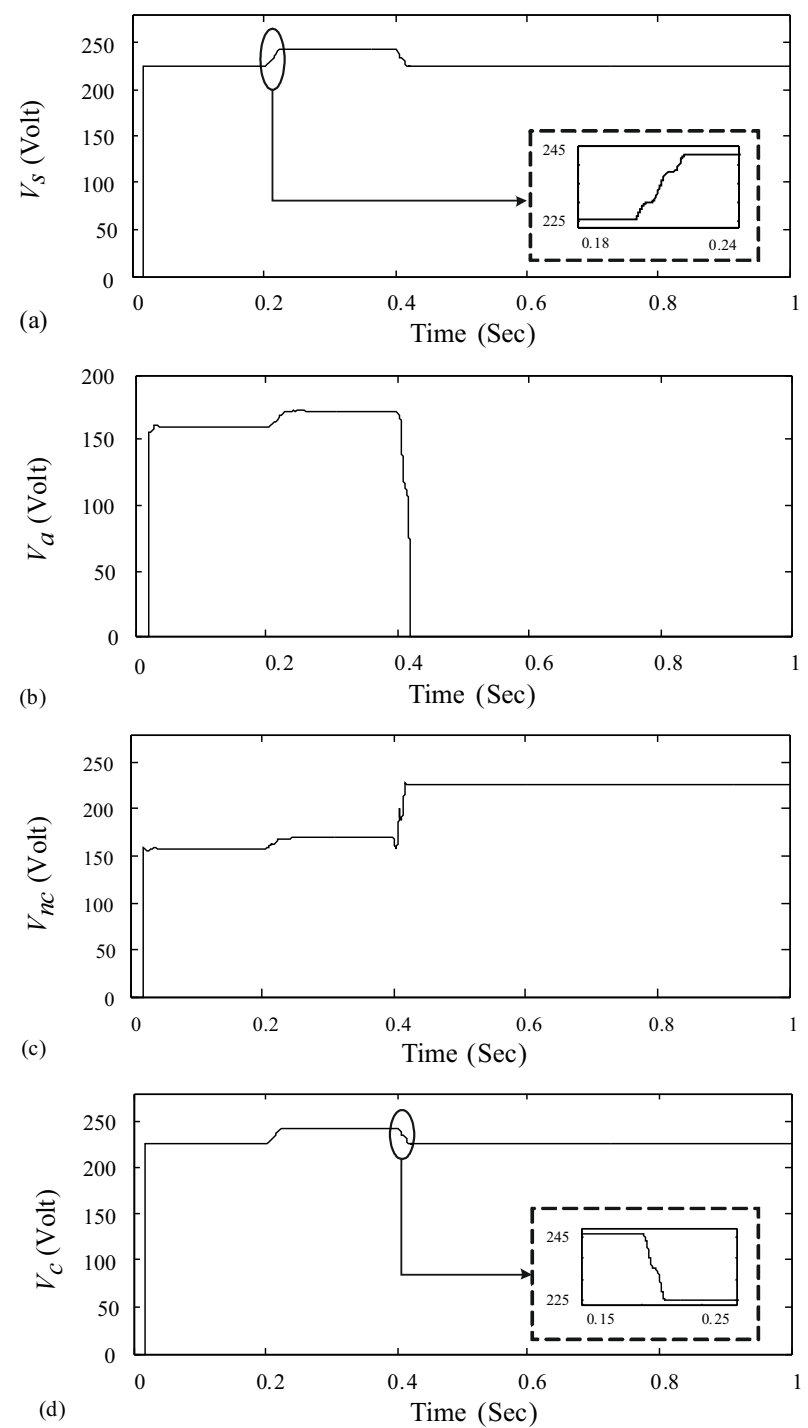

Fig. 6 : Observed RMS value of (a) Source voltage $\left(V_{s}\right)$, (b) Non-critical voltage $\left(V_{n}\right)$, (c) Electric spring voltage $\left(V_{a}\right),(\mathrm{d})$ Critical voltage $\left(V_{c}\right)$ in inductive mode.

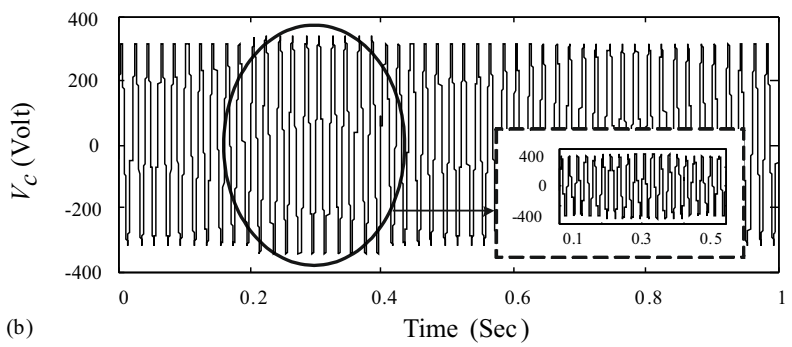




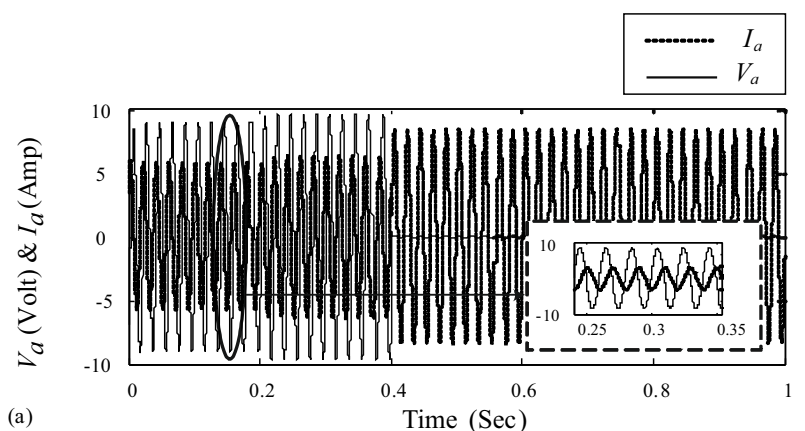

Fig. 7 : Observed Instantaneous value of (a) Source voltage $\left(V_{s}\right)$, Electric spring voltage $\left(V_{a}\right)$ and current $\left(I_{a}\right)$ in capacitive mode.

\section{Discussion}

The intermittent nature of renewable power generation has been identified as a key factor that destabilizes power grid. Such instability problem is expected to become more severe as the amount of intermittent renewable power generation increases. It must be stressed that power system stability must be considered for the design and control of grid connected power inverters. In this section, the recent development of the electric spring technology is summarized. The electric spring concept is proposed to dent the problem caused by the intermittent nature of renewable energy sources such as wind and solar power. This concept can be realized with the help of power electronics technology. Therefore, in this paper the simple close loop control for voltage regulation is proposed. This shows that the system performance of the proposed control scheme is better than the conventional controller in terms of mitigating voltage fluctuations at the common coupling point. The reactive power handling capability of and $\mathrm{ES}$ is governed by the product of the voltage it injects and the current flowing through it. In order to enhance it, high proportion of non-critical load (NC) to the critical load (C) .i.e. NC: $\mathrm{C}=9: 1$, easily helps to restored fluctuated voltage back to its nominal value. Thus effectiveness of an ES improves with the proportion of non-critical load.

The other major power quality problem of three-phase power imbalance can be solved by this control scheme. For this purpose two close loop control i.e. reactive power controller and active power controller respectively can be used. By modulating the control for nonlinear load, ES can also achieve harmonic compensation, power factor correction and voltage regulation simultaneously. Further, the inverters of ES can also be connected back to back which not only reduces the size of the hardware but also extends the controllability of smart load in active power. This type of ES topology could provide a comprehensive solution to mitigate both voltage and frequency problems. With the help of droop control scheme i.e. many ES of small VA rating can be embedded in distributed manner which not only increases the overall efficiency of the power distribution network but also ES can be made to work together without an information and communication technology (ICT). When the concept and operations of Electric Spring are compared with other devices (like FACTS devices and custom power devices) it is observed that the ES can be considered similar to Static Synchronous Series Compensator (SSSC) and different from DVR \& STATCOM. The ES is installed is series with a load along with another load connected in parallel while DVR or STATCOM installed only in series with a single load. When compared with STATCOM it can be observed that ES needs less power rating. Another difference is that the ES can be applied in low voltage side for the end users, while the STATCOM usually installed on transmission system or medium voltage distribution network. A further point of differentiation is that the ES can provide reactive power compensation in a distributed manner whereas the STATCOM provides centralized reactive power compensation. The most important difference is that the ES uses an input signal control to regulate its input voltage. Finally, from the research conducted confirms several advantages of the ES such as voltage regulation, shaping the non-critical load demand to follow power generation profile, reduction of gap between power generation and demand, reduction of energy storage, power factor correction, individual ESs working together without the help of information and communication technology and the possibility of providing both distributed voltage and frequency stability for power grid.
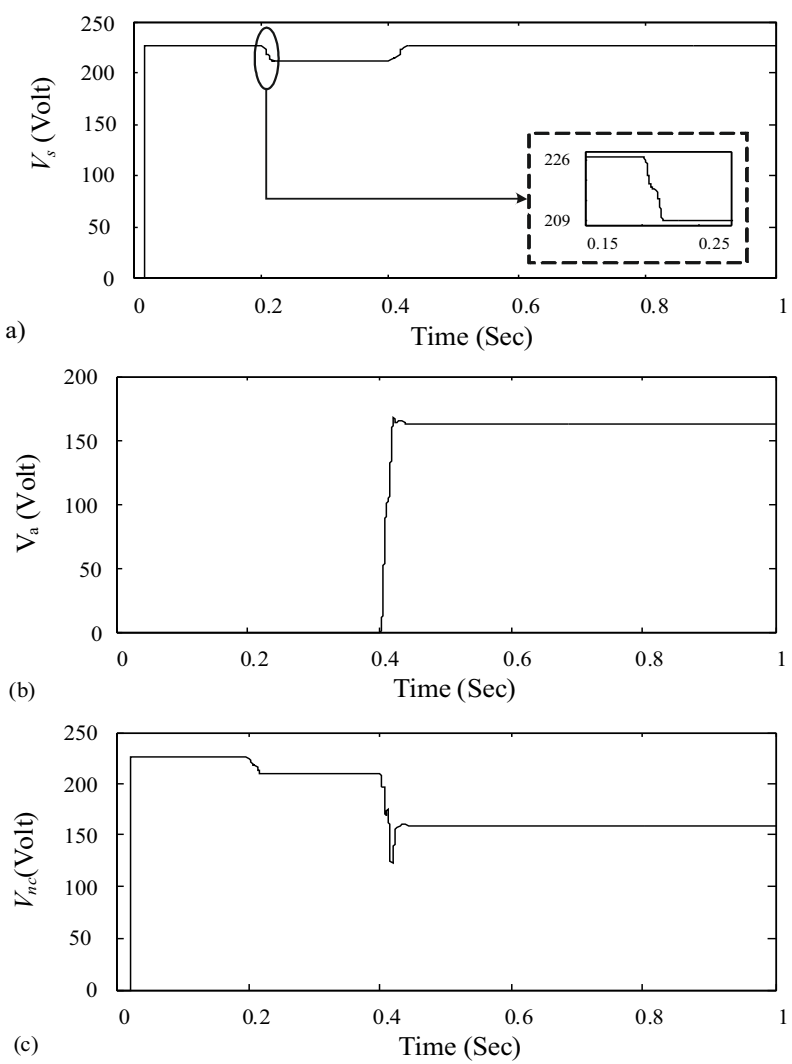


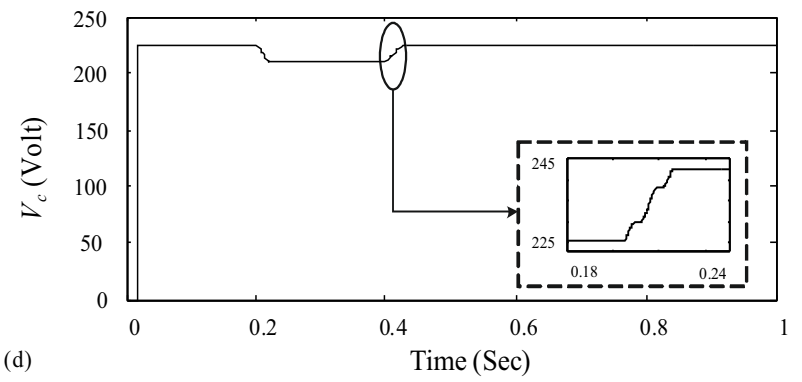

Fig. 8 : Observed RMS value of (a) Source voltage $\left(V_{s}\right)$, (b) Non-critical voltage $\left(V_{n c}\right)$, (c) Electric spring voltage $\left(V_{a}\right),(\mathrm{d})$ Critical voltage $\left(V_{c}\right)$ in capacitive mode.

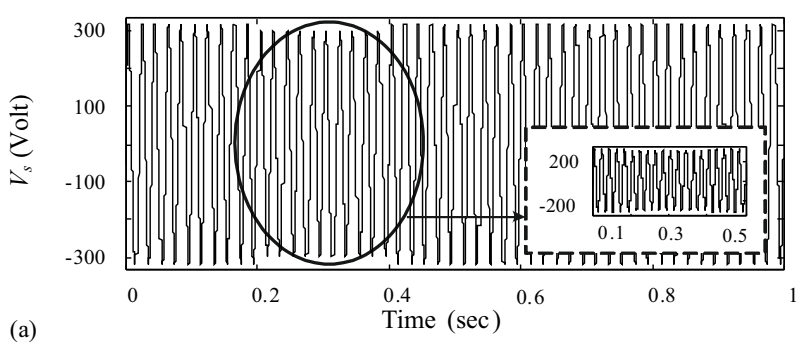

(a)
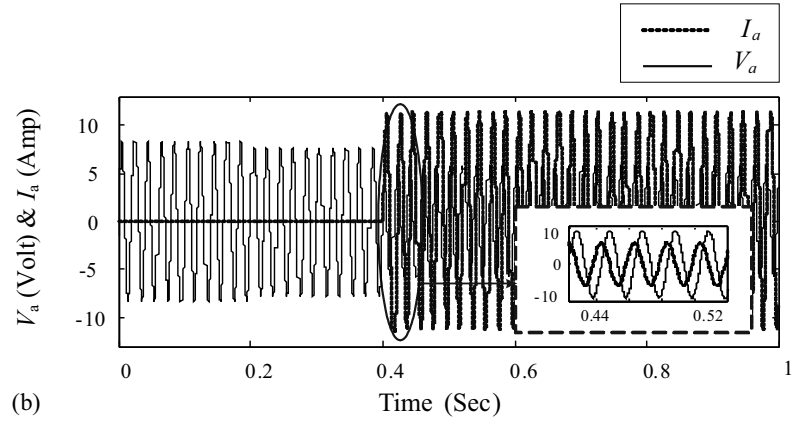

Fig. 9 : Observed Instantaneous value of (a) Source voltage $\left(V_{s}\right)$, Electric spring voltage $\left(V_{a}\right)$ and current $\left(I_{a}\right)$ in capacitive mode.

\section{Conclusion}

The paper proposes new approach for regulating the mains voltage using MLI based ES for smart grid applications. The implemented Three-level CHMLI based ES for smart grid application effectively regulates the ac mains voltage and reduces the THD content as compared with Two-level VSI based ES. The effectiveness of ES is validated through digital simulation in terms of THD. Lastly simulation results of droop control for Four Electric springs have been implemented in a large-scale distributed pattern in order to make multiple ES act in coordinating manner so as to have robust stabilizing effect.
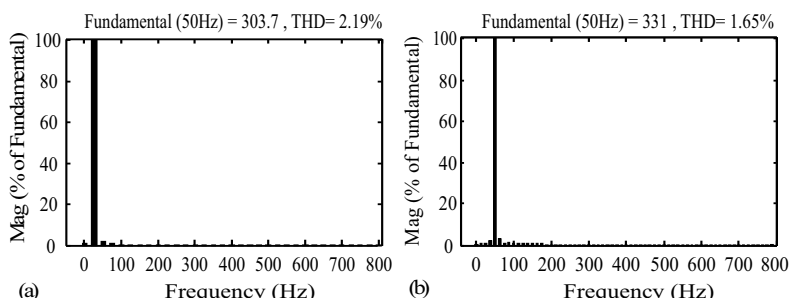

Fig. 10 : THD analysis of (a) Two-level and (b) Three-level CHMLI based ES.

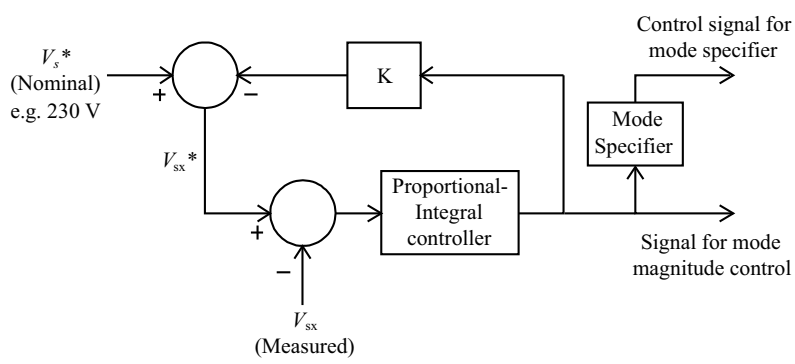

Fig. 11. Modified control scheme for providing an automatically adjustable reference voltage "Vsx_ref".

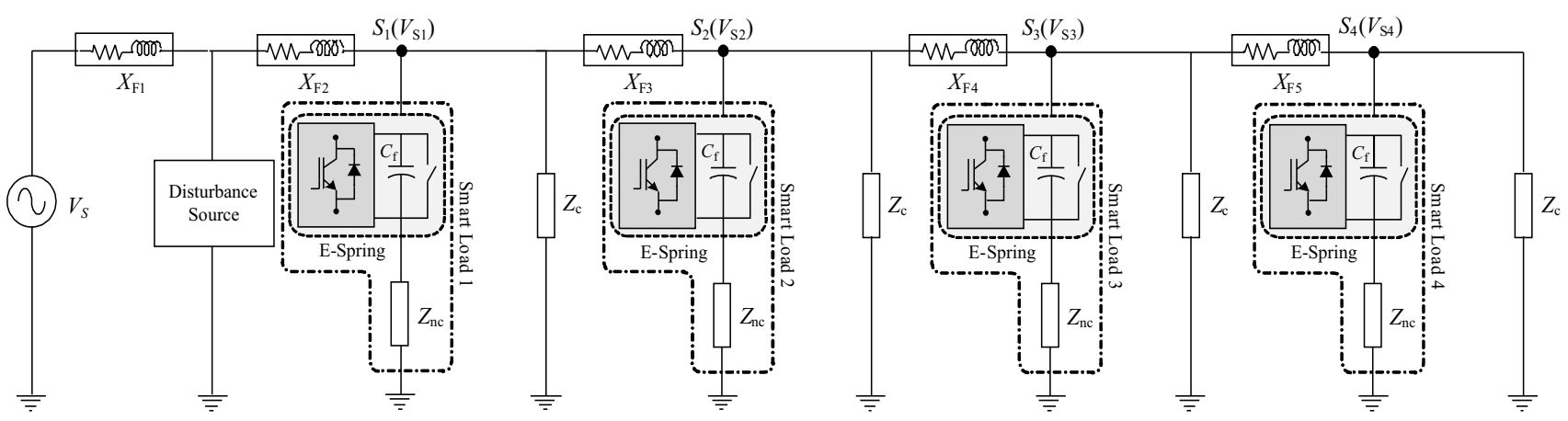

Fig. 12 : Single Phase diagram of the power grid and loads (with four distributed electric springs working as a group). 


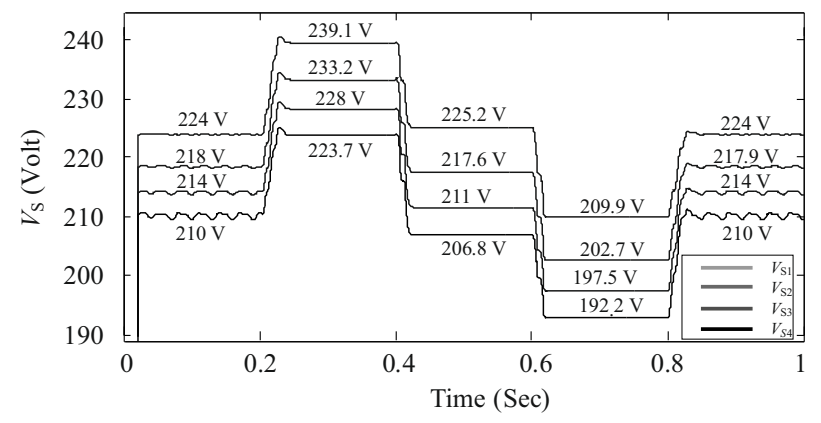

Fig. 13 : Measured RMS value of mains voltage $V_{s 1}, V_{s 2}, V_{s 3}, V_{s 4}$

\section{Acknowledgment}

The authors are grateful to the RTNMU University and Yeshwantrao Chavan Collage of Engineering, Nagpur, for providing special funds under Innovative Project Scheme \& In-house Project Proposal Grand 2016-17.

\section{References}

[1] Edward J.Coster, Johanna M.A.Myrzik, BAS Kruimer, "Integration Issues of Distributed Generation Distribution Grids," Proceedings of the IEEE, Vol.99, No.1, pp.28-39, January, 2011.

[2] Koutsopoulos and L. Tassiulas, "Challenges in demand load control for the smart grid," IEEE Netw., Vol. 25, No. 5, pp. 16-21, 2011.

[3] M.H.J.Bollen, "Understanding Power Quality Problems: Voltage Sags and Interruptions," IEEE Press, 2000.

[4] N. Hingorani and L. Gyugyi, Understanding FACTS, Concepts and Technology of Flexible AC Transmission Systems. New York: IEEE Press, 2000.
[5] M. Parvania and M. Fotuhi-Firuzabad, "Demand response scheduling by stochastic SCUC," IEEE Trans. Smart Grid, Vol. 1, no. 1, pp. 89-98, Jun. 2010

[6] D. Westermann and A. John, "Demand matching wind power generation with wide-area measurement and demand-side management," IEEE Trans. Energy Convers. Vol. 22,No. 1, pp. 145-149, Mar. 2007.

[7] X. Chen, Y. Hou, S. C. Tan, C. K. Lee, and S. Y. R. Hui, "Mitigating voltage and frequency fluctuation in microgrids using electric springs," IEEE Trans. Smart Grid, Vol. 6, No. 2, pp. 508-515, Mar. 2015.

[8] P. Sauer, "Reactive power and voltage control issues in electric power systems," in Applied Mathematics for Restructured Electric Power Systems. New York: Springer.

[9] Jose Rodriguez, Jih-Sheng Lal, Fang ZhengPeng, "Multilevel Inverter: A survey of Topologies, Control, and Applications". IEEE Trans. on Industrial Electronics, Vol.49, No.4, pp. Aug. 2002.

[10] Z. Du, L. M. Tolbert, J. N. Chiasson, and B. Ozpineci, "A cascade multilevel inverter using a single fuel cell DC source," in Proc. IEEE APEC, Dallas, TX, Mar. 2006, Vol. 1, pp. 426-430.

[11] Shu Yuen(Ron) Hui, Chi Kwan Lee, and Felix F. $\mathrm{Wu}$, "Electric springs- a new smart grid technology," IEEE Trans. Smart Grid, Vol. 3, No. 3, pp. 1552-1560, Sep. 2012.

[12] C. K. Lee, B. Chaudhuri, and S. Y. Hui, "Hardware and control implementation of electric springs for stabilizing future smart grid with intermittent renewable energy sources," IEEE J. Emerg. Sel. Topics Power Electronics, Vol. 1, No. 1, pp. 18-27, Mar. 2013. 